\title{
Breve análise sobre a relação homem e sociedade
}

\section{Gustavo Fronza de Prá}

Resumo: $O$ trabalho realizado tem por objetivo resgatar uma análise individualiza sobre o homem e a sociedade, posteriormente fazendo a correlação de ambos. $\mathrm{O}$ homem nasce já inserido no meio social e nele deve fazer história, mas deve fazer a sua história e não aquela que a doxa societária impõe. Para isso é necessário um maior conhecimento de si, enquanto indivíduo. A sociedade também deve ser entendida e transcendida, visto que contém como função única possibilitar que o sujeito realize a si mesmo. É necessária a capacidade e a decisão de conhecer a si mesmo e mudar o modo de pensamento até então formado pelos estereótipos sociais fazendo ação ao projeto ôntico.

Palavras-chave: Homem; Sociedade; Critério.

\section{Brief analysis on the relation between man and society}

Abstract: This work has the objective to bring back an individualized analysis on man and society, doing, then, the correlation between them. Man is already born in the social environment and must make history in it but has to make his own path and not the opinions imposed. It is necessary, for this, a higher selfknowledge, as individual. Society also must be understood and transcended, as it carries as only function the enablement for the individual to fulfill himself. It is necessary the capacity and the decision to self-knowledge and change the way of thinking formed until that moment by social stereotypes, making the action in direction to the ontic project.

Keywords: Man; Society; Criterion.

\section{Breve análisis sobre la relación hombre y sociedad}

Resumen: El trabajo realizado tiene por objetivo rescatar un análisis individualiza sobre el hombre y la sociedad, posteriormente haciendo la correlación de ambos. El hombre nace ya inserto en el medio social y en él debe hacer historia, pero debe hacer su historia y no aquella que la doxa societaria impone. Para ello es necesario un mayor conocimiento de sí, como individuo. La sociedad también debe ser entendida y trascendida, ya que contiene como función única posibilitar que el sujeto se realice a sí mismo. Es necesaria la capacidad y la decisión de conocerse a sí mismo y cambiar el modo de pensamiento hasta entonces formado por los estereotipos sociales haciendo acción al proyecto óntico.

Palabras clave: Hombre; Sociedade; Criterio. 


\section{Introdução}

De modo teórico esta pesquisa trata de uma análise breve de alguns itens que caracterizam tanto o indivíduo, como a sociedade. Qual a relação que há entre eles? É possível ao indivíduo estar dentro da sociedade sem ser por ela sucumbido? A pesquisa baseia-se na ótica Ontopsicológica, com a temática sobre o organísmico do social.

Cada pessoa possui intato em si um projeto de natureza, algo que lhe é próprio e lhe dá a identidade de ser quem verdadeiramente é. Em cada indivíduo há um projeto diferente do outro, sem nunca se repetir, pois, como as pessoas, eles também são diversos. A única questão que lhes é igual está no fato de que ele deve se tornar realidade no meio social para que o sujeito "cumpra sua missão" neste planeta. É como no exemplo do copo, isto é, pensemos que cada um possui um copo de tamanho diferente (este copo pode ser considerado o projeto de natureza) e, é necessário enche-lo sem que falte ou sobre conteúdo, isso faz com que se chegue à realização plena de si mesmo e esteja constantemente em estado de graça, emanando, a partir disso, esta vitalidade e funcionalidade para o meio social no qual se encontra.

O sujeito somente poderá promover o bem-estar para o social depois de estar realizado consigo mesmo, ter compreendido tantas coisas a cerca de si, ou seja, feito a metanoia $^{l}$ para poder trabalhar e realizar aquilo que verdadeiramente lhe cabe na história. Este processo deve ser feito com acompanhamento de um profissional Ontopsicólogo em uma Consultoria de Autenticação, possibilitando ao sujeito descobrir onde estão suas maiores virtudes, assim como suas falhas, onde está errando e em virtude de qual motivo. Ao final, deixa o comportamento de erro, estereotipado, em consonância com a intencionalidade do Em Si ôntico. Ao contrário desse processo, o que comumente vemos são as ações pensadas boas para a sociedade, mas que são apenas compensações de frustrações que cada um não definiu em si deslocando-a para o social como tentativa de resolução. Erra duplamente, pois, não resolve a si próprio e ainda fortalece a estrutura corrompida da sociedade.

Não vemos essa estrutura, mas ela existe e dita os modos de ação de cada indivíduo, que unidos, formam uma grande massa de repetidores. Enquanto o indivíduo faz a sociedade a sociedade faz o indivíduo, é uma relação mútua que não se pode fugir, ao

\footnotetext{
${ }^{1}$ A mudança de mente. Mais em: MENEGHETTI, A. Dicionário de Ontopsicologia, 2012, p. 172.
} 
contrário, ser entendida e transcendida. O Acad. Professor Antonio Meneghetti (2014) afirma a existência de uma estrutura que não muda, ele a chama de flutuante. Sobre isso, prossegue o fundador da Ontopsicologia:

Concretamente é o magma, as corporações, estruturas e infraestruturas coligadas de um modo que enovela todo o mundo. Os tijolos, as pedras, as pequenas técnicas que compõem essa estrutura flutuante são os jornais, a televisão, a rádio, juntamente a canções, música, cinema, teatro, moda, marketing oficial e paralelo, $s m s$, celulares, política com relativas palavras e instrumentações, as informações que passam boca a boca, as várias concepções sobre sexo, família, voluntariado, associações, proteção civil, animalistas, ecologistas, no global. (MENEGHETTI, 2014, p. 85).

Verifica-se então, que isso esta presente em praticamente tudo que se conhece, ou melhor, em tudo praticamente que o homem criou e agora manobra conforme o interesse de poucas mentes que decidem qual caminho toda uma população irá seguir. Com um simples exercício de imaginar quantas vezes uma pessoa age por vontade e pulsão propriamente suas e quantas vezes age por uma informação implantada em si mesma é facilmente perceptível que as ações, na maioria das vezes, seguem um padrão já definido e induzido pelo meio social. Um exemplo simples é de uma mulher sempre assistindo uma determinada propaganda de uma marca famosa de roupas e por fim adquirindo o item da publicidade. Mas o ato não foi feito porque realmente lhe seria útil naquele momento, mas porque supre-se a falsa necessidade, o desejo de ser aceita pela massa, de ter aceitação em determinado grupo.

É necessário que se possa entender que sempre em primeiro plano deve estar o indivíduo e não a sociedade. Primeiramente a própria individualidade existencial, depois o social. Obviamente, não se pode conviver sem o social, a relação sempre irá acontecer. Mas pode-se estar presente, conviver sem fazer parte deste meio, resguardando em si a própria verdade. De acordo com Meneghetti: 
No final, compreende-se que muitas verdades absolutas não passam de estereótipos, opiniões prefixadas de conduta de determinados grupos étnicos, políticos, histórico-culturais, econômicos, religiosos. É necessários aprender muitas estradas para compreender onde está a vida. A vida usa todas, mas não reside em nenhuma. Tudo é relativo ao próprio devir. Somente a verdade de si mesmo, no final, é absoluta; porque, depois, esse é o único valor relativo onde o ser joga. (MENEGHETTI, 2012, p. 56-57).

Salienta-se que o presente trabalho foi escolhido visando propiciar um maior conhecimento diante da díade: homem $x$ sociedade, evidenciando suas características relevantes para que os leitores possam fazer uma revisão existencial e técnica de si mesmos. O tema possui suma importância pelo fato de expor uma análise individuada em um primeiro momento das noções de homem e sociedade e, posteriormente, abordando a relação entre os dois. Destaca-se que, para uma sociedade mais funcional são necessárias pessoas mais funcionais em conformidade com a lógica da vida. Isto parte sempre de forma inicial presente na intimidade de cada indivíduo. A ciência Ontopsicológica traz diversas passagens de solução e evolução, as quais serão discutidas no decorrer do texto, o qual se desenvolveu por meio da metodologia de estudo teórico em livros e revistas.

\section{Fundamentação Teórica}

\subsection{Indivíduo}

\subsubsection{Quem é o homem?}

Segundo o Dicionário de Ontopsicologia, o homem é uma "unidade de ação histórico-espiritual constituída por um projeto ôntico em acontecimento terrestre, com faculdades ou funções inteligentes, racionais, emocionais, biológicas” (MENEGHETTI, 2012, p. 128). Então, é todo um composto que atua, ou melhor, deveria atuar o projeto ôntico, citado anteriormente, dentro da existência. Isso quer dizer, não entrando no mérito da composição físico-biológica humana, que estando dentro da existência cada pessoa possui um direcionamento já pré-definido em sua vida. Por exemplo, um homem que quando criança o que mais fazia era construir coisas, casas, brinquedos, ele nasceu com o dom de construir, foi desenvolvendo isso quando pequeno. Chegando à escola também tem enorme facilidade com matemática, física, química e adora estudar isso. Já quando 
adolescente escolhe prontamente seu curso de faculdade: engenharia civil. Forma-se, se especializa com outros cursos de qualificação e começa a construir grandes prédios, monumentos, sendo sempre requisitado o seu trabalho. Isto é, esse é o caminho trilhado por quem segue sua ordem de natureza, seu projeto ôntico. É importante ressaltar que poucas pessoas realizam esse percurso de autenticidade.

Ainda no livro, Dicionário de Ontopsicologia, há a definição para "autóctise”, que é o "processo histórico de escolhas existenciais que fazem a resultante da evolução e da situação pessoal" (MENEGHETTI, 2012, p. 31). Isto é, é a auto constituição, o sujeito que faz de sua vida um espelho do que o seu projeto reflete, segue a ordem já impostada pela vida e não aquela que a sociedade criou.

\subsubsection{Estereótipos do homem}

O Dicionário Ontopsicológico traz a seguinte definição de estereótipo: "Um modelo de comportamento geral que se faz referência de outros semelhantes e que se torna valor de apoio para individuar segurança e razão dialética com a sociedade" (MENEGHETTI, 2012, p. 99). Trata-se de um comportamento fixo que o sujeito adquire quando jovem e acaba repetindo-o ao longo dos anos por ser algo que ele pensa "funcionar". Na realidade, o estereótipo é sobremaneira neutro, ou seja, tudo depende da forma como é utilizado pela pessoa e é mais simples quando se olha os resultados, por exemplo, quando uma pessoa que sempre está vestida de terno decide ir a praia, mas não troca de roupa, obviamente, para aquela situação o traje seria outro, estando então sujeita a sofrer as consequências do sol, da areia e não poderá aproveitar o que aquela situação poderia lhe oferecer.

O Acad. Prof. Antonio Meneghetti traz, em sua obra Os Jovens e a Ética ôntica (2013), aspectos variados e aprofundados sobre os estereótipos, destacando aqueles predominantes na juventude, a saber, biologismo, idealismo crítico e consumismo ${ }^{2}$.

No biologismo existe, sempre por parte da pessoa, uma valoração infinita ao corpo e aos seus prazeres. O problema é que se permanecer neste aspecto nunca poderá vir a ser um líder, pois, será no máximo um reprodutor de sua espécie.

\footnotetext{
${ }^{2}$ Conteúdo presente no capítulo intitulado Os desvios da juventude mundial, presente em: MENEGHETTI, A. Os Jovens e a ética ôntica. Recanto Maestro: Ontopsicológica Editora Universitária, 2013, p. 49.
} 
O idealismo crítico acontece com aqueles que no início demonstraram uma diversa capacidade intelectiva, de conhecimento e ao invés de investirem nisso, ficam estagnados, apostam ser os mais espertos e inteligentes. O problema é que com essa mentalidade há a ilusão de já ter chegado ao máximo, não pagando o preço justo para crescer.

No problema do consumismo, evidencia-se um autocondicionamento pertencente a um sistema mundial que tem por objetivo engessar as pessoas em determinados padrões de pensamento e atitude. Sem contar que também existem os outros tipos de estereótipos, vícios e limites que bloqueiam o crescimento natural do ser humano.

\subsubsection{Metanoia}

O Dicionário de Ontopsicologia trata a metanoia como "mudança de mente". Segundo Meneghetti, é uma "variação radical do comportamento para identificá-lo à intencionalidade do Em Si. Reorganização em evolução progressiva de todos os modelos mentais e comportamentais" (MENEGHETTI, 2012, p. 172).

É um processo realizado em conjunto de um profissional Ontopsicólogo, que com algumas análises pode colher rapidamente o ponto onde a pessoa erra contra si mesma, pois, não estaria permitindo que todo seu potencial florescesse para que assim fosse possível atingir a realização plena de si mesma. Todos devem passar pelo processo, porque todos de alguma maneira foram construídos com determinadas coisas que não pertenciam à própria identidade. Essa mudança tem o objetivo de limpar tudo isso, deixando e destacando o que realmente for próprio, o que for o Em Si ôntico. O resultado será de uma reestruturação e por fim de uma nova leitura da realidade sendo mais funcionais para si e, consequentemente, para a sociedade.

\subsubsection{Em Si ôntico}

O Em Si ôntico, todos o possuem, mas às vezes não existe um contato mais direto com ele, ou seja, acontece a não atuação da vontade do Em Si ôntico na história pessoal do sujeito. Segundo o Dicionário de Ontopsicologia, Em Si ôntico é o "projeto-base de natureza que constitui o ser humano" (MENEGHETTI, 2012, p. 84). É considerado o critério-base da identidade do indivíduo. O Em Si ôntico também pode ser alma, não no sentido religioso, mas como consta na sua etimologia, algo que forma e dá movimento a matéria orgânica. O Acadêmico Professor Anotnio Meneghetti constatou que existem 15 
características possíveis de identificar a presença autenticada do Em Si ôntico em uma pessoa: Inseico, Holístico-dinâmico, Utilitarista-fincional, Virtual, Econômicohierárquico, Vencedor, Alegre, Criativo, Espiritual ou Transcendente, Agente no interior de um universo semântico, Mediânico entre o ser e a existência histórica, Histórico, Estético, Volitivo-intencional e Santo (MENEGHETTI, 2014. p. 58). Ainda mais, sobre o Em Si ôntico e sua conscientização pelo sujeito humano, afirma Meneghetti:

O importante é que o homem deve saber construir uma consciência, um Eu interativo, côngruo, coincidente com a pulsão do Em Si ôntico. Da Bipolaridade de Eu lógico-histórico e Em Si ôntico, faz-se a infinita dialética do devir da pessoa.(MENEGHETTI, 2014, p. 57).

Por fim, trata-se de compreender que a dimensão lógico histórica não contempla a totalidade do sujeito, mas, antes disso, ele deve fazer identidade com o todo, isto é, executar em si o apelo transcendental que lhe é próprio, o fundamento ôntico.

\subsubsection{Estilo de vida}

Depois de realizada a metanoia não se pode parar de evoluir e crescer, pois, é um ato cotidiano o reforço e preservação da própria identidade. Se não é feito isso é normal e frequente o retorno ao formato que se era antes. Deste modo, apenas com um estilo de vida adequado ao seu Em Si ôntico se conserva a naturalidade do projeto real e verdadeiro. De nada adianta fazer um processo de psicoterapia (o qual vem a resultar na metanoia), sem a mudança de comportamento nas pequenas coisas do dia a dia, ali onde o sujeito ganha ou perde a si mesmo. A mudança, portanto, deve ser integral: atitudes, mentalidade, relações, trabalho, estudo, cultura, comportamento etc.

\section{2 Sociedade}

A sociedade nada mais é do que um agrupamento de seres que convivem harmoniosamente, ou deveriam assim conviver. A vida em sociedade pode ser formada tanto por humanos, como também por animais. A palavra é origina-se de socius, que

significa "companheiro", originalmente "seguidor", relacionado com o verbo sequi, 
"seguir, ir junto, acompanhar" segundo o dicionário etimológico online Origem da palavra ${ }^{3}$.

Meneghetti (2014), no livro A Crise das Democracias Contemporâneas diz que a sociedade é sempre aquilo que relaciona-se ao estado de associação, seja entre amigos, companheiros, ou firmada em âmbito maior. Também Thomas Hobbes ${ }^{4}$, na Modernidade, afirmou que a origem da sociedade se deu pelo fato da conquista de uma maior segurança, o contratualismo, o acordo firmado entre homens visando a ordem da vida social. A mesma defesa foi feita por Jean-Jacques Rousseau ${ }^{5}$, afirmando que o homem trocou parte da sua liberdade visando maior bem-estar social. Depois, tantos outros filósofos e sociólogos explanaram suas ideias acerca de como surgiu o fenômeno social. Diferentemente, o fundador da Ontopsicologia aborda o assunto afirmando que a origem da vida social tem seu fundamento no fato de que o homem já possui em si mesmo a capacidade de relacionamento, portanto, não se deve ao fato de querer segurança e bemestar, antes mesmo disto há no homem o princípio relacional.

\footnotetext{
Analisando o homem - enquanto indivíduo, pessoa, criatura - observa-se que tem tudo do seu intrínseco modo de existir para se definir sociável. Tem uma situação, uma constituição, um devir que o titula, compreende e define como ente sociável. Não se pode compreender o homem se excluirmos essa constatação. Essa sociabilidade é inata, estrutural, específica do humano enquanto existente por quanto se observa neste planeta (MENEGHETTI, 2014, p. 71-72).
}

Portanto, a vida em sociedade é dimensão intrínseca à existencial fenomenal do homem no mundo. A constituição do homem passa por esse aspecto.

\subsubsection{Estereótipos Sociais}

O grande mal que ocorre através das relações sociais relaciona-se ao surgimento dos chamados estereótipos sociais, os quais padronizam ações dos seres humanos. Quando uma criança, por exemplo, nasce dentro de uma determinada sociedade, ela já será condicionada pelos estereótipos do local, mas não quer dizer que aquilo que ela irá acreditar e se tornar futuramente seja o que seu projeto de natureza aciona em seu interior.

\footnotetext{
${ }^{3}$ Disponível em: origemdapalavra.com.br/site.

4 1588-1679.

5 1712-1778.
} 
Assim formam-se os indivíduos frustrados existencialmente, aqueles que não seguiram o que o projeto de natureza determinou. $\mathrm{O}$ sujeito estereotipado e frustrado poderá ter grandes coisas, ter estudado, trabalhado bastante e com isso ganhado dinheiro para comprar uma bela casa, carro, ter constituído uma família. Entretanto, inconscientemente terá consigo um ponto de angústia, que não consegue compreender. É ali onde a vida cobra a escolha, mesmo que inconscientemente, da não realização de si mesmo.

Os estereótipos sociais são tantos e variados, são incontáveis, mudando de cultura a cultura, mas sempre estão presentes na sociedade. A família é um exemplo clássico de estereótipo, muitas pessoas o vivem através do objetivo de criar e fazer a manutenção de uma família feliz como condição de felicidade. Mas isso não é necessariamente um fato verdadeiro visto que o sujeito antes deveria chegar ao sumo de si mesmo em todos os aspectos, antes disto é somente compensação.

\subsubsection{O Meme}

De acordo com o Dicionário de Ontopsicologia (2012) o "meme" é considerado um "formal informacional agregado, programado", "imitação elaborada sem referência a um concreto gênico" (MENEGHETTI, 2012, p. 162). O meme é difundido em enorme escala pela facilidade da era da globalização atual sempre levando diferentes informações que não são reversíveis ao concreto real da vida, mas sim elemento vindo da "massa", informações e elementos esses que se transformam em hábitos, enraizando-se e massificando a vida social. Antonio Meneghetti, em seu Manual de Ontopsicologia, afirma:

\footnotetext{
Dada a natureza interdisciplinar da ciência que se ocupa dele, é possível dar-lhe várias definições, mas a mais completa talvez seja aquela que o indica como uma ideia que, uma vez colocada em um cérebro que a hospede, influencia os eventos de modo tal a criar outras cópias de si mesma, que irão se instalar em outras mentes. (MENEGHETTI, 2010, p. $66)$.
}

\subsubsection{A Estrutura flutuante}

A denominada estrutura flutuante é consistência e permanência dos estereótipos e memes em âmbito social através de tempos e culturas. De acordo com Meneghetti, é aquilo 
que se instala e nunca muda (MENEGHETTI, 2014). Ou seja, a estrutura flutuante esta tão impregnada na sociedade que dificilmente as pessoas percebem sua existência. A estrutura flutuante pode ser constatada a partir de dois objetivos que lhe são inerentes: "a) incrementar a economia das próprias estruturas e bancos; e b) criar exigências fictícias, as carências - como necessidade - superiores àquelas primárias (comer, beber, dormir)" (MENEGHETTI, 2014. Pág, 86). Desse modo, para incrementar a economia acontece a criação de necessidades extra, fora daquelas básicas do ser humano voltando-se, sobretudo, ao estereótipo do consumismo.

Um jovem acaba sendo refém do estereótipo do consumismo difundido entre a grande massa quando fica à mercê de informações dos pequenos componentes da estrutura flutuante, presente nos jornais, na televisão, na internet, na rádio, em toda a parte, inventando e implantando desejos que não são naturais nos indivíduos. Um caminho para ir em direção contrária a isso é a metanoia.

\section{Método}

O presente trabalho, realizado na forma de estudos bibliográficos, em livros, revistas, sites e materiais audiovisuais buscou evidenciar três momentos, o primeiro é elucidar de modo bastante simples quem é o homem existente neste planeta, como ele se constrói ao longo do tempo e como perde e como retoma a própria identidade. O segundo momento, é trazido elementos de estruturação da sociedade, o que ela é e como é formada, tendo o ponto de solução no terceiro momento. O terceiro momento é realizado nos resultados e discussões e procura interagir os dois primeiros momentos com o objetivo de indicar ao homem como fazer uma relação funcional dentro da sociedade preservando a sua identidade.

\section{Resultados e Discussão}

Depois de observadas as questões que dizem respeito ao homem e à sociedade, chega-se a conclusão de que ambos são requisitos constituintes um do outro. Havendo no homem um projeto de natureza a ser realizado na história, este deve fazê-lo em meio à sociedade, não existe outra maneira de realiza-lo fora dela. O escopo do homem é realizado sempre no plano social, na sociedade. Entretanto, a metanoia exige que o homem veja primeiro a si 
próprio. O homem deve ir esclarecendo o que lhe serve como crescimento, principalmente os estereótipos aprendidos na infância, que de certa forma estabilizam o crescimento atual da pessoa. Verificar quais são os estereótipos principais predominantes na sociedade em que convive, também no aspecto da família, amigos, grupo escolar. São sempre lugares onde certamente também estará o sujeito, visto que enquanto o homem faz a sociedade e a sociedade faz o homem, construindo uma relação dialética fortíssima.

Esse é o caminho pelo qual o homem será capaz de entrar em contato com seu Em Si ôntico transcendendo a doxa societária para realizar a si mesmo buscando a vetorialidade na existência. Para exemplificar, pensemos numa semente de araucária. Esta semente possui um projeto, que é fazer a maior árvore de araucária jamais vista, não é fazer a maior laranjeira, o maior limoeiro, mas sim única e exclusivamente a araucária. Logo que ela começar a crescer perceberá que está em uma floresta que está em sociedade com milhares de outras espécies de plantas, mas nem por isso ela deixará de dar o máximo para realizar seu projeto. Do mesmo modo é o indivíduo humano, que se reconhece existindo junto a milhares de pessoas e deve seguir o caminho que lhe foi dado. Quando acontece essa congruência o indivíduo começa a se desenvolver de modo integral contribuindo antes para si e depois também para todos que estão ao seu entorno, ou seja, a sociedade. De acordo com Meneghetti,

\footnotetext{
Ao fazer isto, dá-se satisfação a si mesmo e, portanto, entra-se naquele mundo onde se desfruta alegria. Por meio da Ontopsicologia, teve-se a fortuna de entender que a própria consciência não era exata, mas se teve também a escolha de saber que é possível ver e confrontar-se com o projeto original. Como quer que seja a massa, o gênio da vida é vivo, presente, contemporâneo. Ou seja, cada um deve saber amar sem se deixar poluir, para progredir em qualidade para todos e suma gratificação para si mesmo (MENEGHETTI, 2010, p. 51).
}

Portanto, o homem quando resolve a si mesmo também ajuda a resolver a sociedade, o processo deve acontecer desta forma. Porém, para não ser atacado externamente é preciso reservar o ponto íntimo de si mesmo sem dar-se aos outros por nada em troca, ou seja, seguir e concordar com as regras sociais por fora, mas por dentro manter-se cultivando as regras do próprio Em Si ôntico. Ainda mais, "Deve-se ser 
colaborador no mundo, sem definir-se no mundo; deslizar como a serpente na adaptação, mas com a pomba pronta no coração" (MENEGHETTI, 2012. p. 106).

\section{Considerações Finais}

Conviver com as mais variadas pessoas e suas personalidades diversas, em um primeiro momento pode ser confuso caso se deixe atuar por essas informações. O restante se relativiza. Felizmente, para aqueles que querem há saída, de certa forma quando cada um se encontra em uma dificuldade ou outra, existe também uma ou duas saídas e dizem respeito sempre à opção que o homem faz por si mesmo. Não é no exterior e sim no interior que se deve buscar a solução e a decisão diante das escolhas a serem feitas. Com o estudo da Ontopsicologia aprende-se a conhecer o próprio critério, o Em Si ôntico ou identidade, aprende-se com humildade a responsabilizar-se para decidir viver a si mesmo como valor e atuação.

\section{Referências}

GIDDENS, A. Sociologia. $6^{\text {a }}$ ed. Porto Alegre: Editora Penso, 2012.

MENEGHETTI, A. A arte de viver dos sábios. 3. ed. Recanto Maestro: Ontopsicológica Editora Universitária, 2009.

MENEGHETTI, A. A crise das democracias contemporâneas. Recanto Maestro: Ontopsicológica Editora Universitária, 2014.

MENEGHETTI, A. Dicionário de Ontopsicologia. 2. ed. Recanto Maestro: Ontopsicológica Editora Universitária, 2012.

MENEGHETTI, A. Direito, Consciência, Sociedade. Recanto Maestro: Ontopsicológica Editrice, 2009.

MENEGHETTI, A. Do humanismo histórico ao humanismo perene. Recanto Maestro: Ontopsicológica Editora Universitária, 2014.

MENEGHETTI, A. Manual de Ontopsicologia. 4. ed. Recanto Maestro: Ontopsicológica Editora Universitária, 2014.

MENEGHETTI, A. Nova Fronda Virescit: introdução à Ontopsicologia para jovens. Recanto Maestro: Ontopsicológica Editora Universitária, 2014. 
MENEGHETTI, A. Nova Fronda Virescit: introdução à psicoterapia ontopsiológica, instrumentos e aplicações. Recanto Maestro: Ontopsicológica Editora Universitária, 2014.

MENEGHETTI, A. Nova Fronda Virescit: em busca da alma. Recanto Maestro: Ontopsicológica Editora Universitária, 2010.

MENEGHETTI, A. Os jovens e a ética ôntica. Recanto Maestro: Ontopsicológica Editora Universitária, 2013.

MENEGHETTI, A. Pedagogia Ontopsicológica. 3. ed. Recanto Maestro: Ontopsicológica Editora Universitária, 2010.

MENEGHETTI, A. Projeto Homem. 3. ed. Recanto Maestro: Ontopsicológica Editora Universitária, 2011.

MENEGHETTI, A. Sistema e Personalidade. 3. ed. Recanto Maestro: Ontopsicológica Editrice, 2004. 